\title{
LA CATEGORÍA JURÍDICA DE LOS "SERVICIOS PRIVADOS DE INTERÉS PÚBLICO”. EL CASO DE LAS JUNTAS DE VIGILANCIA DE RÍOS
}

\author{
THE JURIDICAL CATEGORY OF "PRIVATE SERVICES THAT ARE OF \\ PUBLIC INTEREST". THE CASE OF RIVERS SURVEILLANCE BOARDS
}

\section{Christian Rojas Calderón*}

\begin{abstract}
RESUMEN: En este trabajo se expondrán los antecedentes de la actual configuración de los servicios públicos, introduciendo y caracterizando la tipología de de los Servicios Privados de Interés Público (SPIP). Enseguida, se analizará un caso -las juntas de vigilancia de ríos- a nivel fáctico y normativo. Finalmente se verificará la adecuación de la figura de los SPIP al caso estudiado, y en especial en qué medida o con qué límites se cumplen sus prescripciones teóricas en contraste con la realidad. Cierran este trabajo, las conclusiones correspondientes.
\end{abstract}

Palabras clave: Servicio público, servicio privado de interés público, juntas de vigilancia.

ABSTRACT: This article explains the background of the current configuration of public services, introducing and characterizing the types of Private Services of Public Interest (SPIP, for its name in Spanish). Following, there is the analysis of one case -rivers surveillance tables- on a factual and normative level. Finally, the adequate representation of the SPIP will be verified through the analyzed case, and especially how and up to what limit its theoretical prescriptions are honored as opposed to reality. The closure of the article contains the corresponding conclusions.

Key words: Public Service, Private Service of Public Interest, surveillance tables.

\section{INTRODUCCIÓN}

Resulta evidente que en el marco la reconfiguración de los servicios públicos provocada en nuestro país a partir de las privatizaciones de la década de 1980, surge un nuevo modelo de ellos, forzado tanto ideológica como normativamente a partir de los cambios producidos desde la década de 1970 y que solo a fines de la década de 1990 ha empezado a recibir atención dogmática. Luego, parece conveniente hacer una revisión -aunque no sea la primera- de esta figura clásica del Derecho Administrativo para, sin repetir lo que se ha dicho ya, agregar

\footnotetext{
* Profesor Asistente de la Facultad de Ciencias Jurídicas de la Universidad Católica del Norte (Chile). Licenciado en Ciencias Jurídicas, Universidad de Valparaíso (1998). Abogado (2000). Magíster en Ciencia Jurídica (2008) y Doctor en Derecho (2011), Pontificia Universidad Católica de Chile. Correo electrónico: chrojas@ucn.cl. Este trabajo forma parte del Proyecto FONDECYT No 11110453, titulado "El ejercicio de funciones públicas por particulares en la distribución de las aguas. Implicancias desde el Derecho Administrativo, Derecho Constitucional y Derecho de Aguas", del cual el autor es el investigador responsable. Abreviaturas más usadas: DGA (Dirección General de Aguas); CAg (Código de Aguas); CPR (Constitución Política de la República); LOCBGAE (Ley Orgánica Constitucional de Bases Generales de la Administración del Estado); SPIP (Servicios Privados de Interés Público).
} 
una figura casi fronteriza de esta disciplina que sin duda alguna tiene presencia en nuestro sistema jurídico, como es la figura de los servicios privados de interés público ${ }^{1}$.

Para ello, este trabajo se dividirá en tres partes: en la primera, se analizarán las tipologías de servicio público desde un punto de vista dogmático, hablando sobre su reconfiguración. Luego, en la segunda, se analizará fáctica y normativamente el caso de las juntas de vigilancia. Finalmente, en la tercera se verá, en virtud de lo expuesto, si los casos revisados permiten reconocer y afirmar -particularmente en el ámbito de las aguas-, si efectivamente la figura de los servicios privados de interés público es aplicable en nuestro Derecho. Finaliza este trabajo con las conclusiones de rigor.

\section{LA ACTUAL CONFIGURACIÓN DE LOS SERVICIOS PÚBLICOS}

Qué duda cabe, las cuestiones acerca de la noción, el tratamiento y las nuevas vertientes del servicio público han cruzado y siguen cruzando el centro o núcleo del Derecho Administrativo -como una de sus instituciones clave-, y son atraídas permanentemente a las consideraciones estructurales de la disciplina -en su versión del servicio público orgánico o institucional-; así también como, al mismo tiempo, se aplica a ámbitos más alejados de ella y que se vinculan con zonas fronterizas o nebulosas - del "nuevo servicio público-, donde la aplicación de un régimen jurídico-público se torna ya dudoso ya difuso en los sentidos tradicionales. De este modo, conviene ahora detenerse a analizar siquiera en términos amplios, su actual configuración.

En este sentido, lo primero que es posible e incluso preciso señalar a este respecto, es algo sobre la noción de servicio público en general. Y se considera necesario hacer este ejercicio a lo menos de vez en cuando, pues como lo reconoce la mayor parte de la doctrina administrativista, entre manos tenemos un concepto en constante evolución, que va de la mano con el desarrollo de la sociedad y que se concreta en específicas prestaciones que van a depender de las orientaciones de la política y de la economía. Por eso su carácter esencialmente cambiante ${ }^{2}$.

Ahora bien, si se trata de realizar algunos primeros acercamientos generales a la noción -en miras de los intereses específicos de esta investigación-, resulta pertinente diferenciar las ideas orgánicas de las funcionales sobre esta actividad. Ello pues, de lo que resulte de esta diferenciación, hará posible abordar y explicar un modo de actuación material de las Juntas de Vigilancia, sujetas -se adelanta-a las reglas del servicio público del modo en que se explicará más adelante.

\section{LA NOCIÓN TRADICIONAL O ESTRICTAMENTE ORGÁNICA DEL SERVICIO PÚBLICO}

\subsection{Antecedentes de la concepción tradicional o estricta}

Lo que desde luego y en primer término cabe señalar, es que la idea y noción de servicio público, es en extremo heterogénea y difícil de aprehender, saturada de significados

\footnotetext{
1 En adelante, también bajo el acrónimo de SPIP.

2 Lachaume (1989) p. 30. También véase en el mismo sentido, ARiño et al. (2004) pp. 503-508.
} 
múltiples pues al mismo tiempo se refiere a una realidad institucional, a una ideológica y a una noción jurídica ${ }^{3}$, lo que por tanto torna siempre complejo emprender su análisis. De este modo, corresponde delimitar el campo de estudio -siquiera del modo general en que se haráa lo estrictamente jurídico, considerando empero de manera secundaria esas otras cuestiones.

Enseguida y avanzando, es posible afirmar que el servicio público desde un punto de vista orgánico es identificable con el conjunto de entes o instituciones integrantes de la Administración, siendo tan antigua como el Estado moderno que surgió después de la Revolución Francesa, y por ello mismo se le vincula tan fuertemente al Derecho Administrativo, e incluso es posible afirmar que la idea de "servicio público" en sus orígenes más bien fue una noción sociopolítica que sustituía el "servicio al Rey"; en efecto, este servicio prestado al público ahora implica la realización de un conjunto de actividades a través de los cuales se asegura a los ciudadanos la satisfacción de alguna necesidad, sin que se tengan que atender personalmente de ella ${ }^{5}$, con lo cual podría decirse que se hace lo mismo, pero de manera diferente. Así, en esta actividad originalmente se encuentra una idea expansiva de la actividad del Estado que está en la esencia original y comprensiva de esta noción, por lo que resultaba natural que fuera acompañada en la práctica de una creciente y progresiva asunción de actividades que hasta entonces no se habían considerado "estatales" sino que estaban asumidas por los gremios, la Iglesia, las fundaciones, corporaciones, universidades y otros entes representativos del cuerpo social. Todo aquello ocurrió fundamentalmente a partir de principios del siglo XX en virtud de planes de alta intervención pública derivados de profundas crisis económicas, y destinados a reactivar o potencial el desarrollo económico de los países, básicamente de la mano, al mismo tiempo, de ideas keysenianas presentes en la mayoría de las economías del mundo occidental en esos tiempos.

A partir de ello, se llegó a configurar jurídicamente -por medio de una ley general o sectorial-al servicio público considerada como una reserva de actividad a favor de la Administración Pública del Estado o alguna de sus personificaciones, constituyendo esta actividad de servicio público una actividad publificada o, más aun, reservada a la Administración Pública, lo que implica que tal actividad quedaba incorporada al quehacer del Estado y excluida de la esfera de actuación de los particulares, sin previa concesión ${ }^{6}$. De este modo, la base del concepto se estructuró sobre la titularidad estatal de la actividad, en cuanto la creación de un servicio público se hacía por medio de una declaración formal -que la publificaba-, a partir de lo cual dicha actividad originalmente "libre" pasaba luego a ser "administrativa”, en régimen de monopolio de iure, si bien se contemplaban algunas formas o figuras de colaboración ${ }^{7}$.

En dicha virtud, se puede aventurar una noción estricta aplicable -tradicional si se quiere- conforme la cual y bajo estos supuestos, servicio público es aquella actividad propia de la Administración Pública, de prestación positiva, con la cual mediante un procedimien-

\footnotetext{
3 Chevalier (2003) pp. 4-5

4 Silva Cimma (1995) pp. 19-25.

5 AriÑo et al. (2004) pp. 534-535.

6 AriÑo et al. (2004) pp. 537-538.

7 Sendín García (2003) p. 109.
} 
to de Derecho público, se asegura la ejecución regular y continua, por organización pública o delegación, de un servicio técnico indispensable para la vida social ${ }^{8}$.

Esta misma concepción -tradicional, orgánica, estricta o positiva-, que consideraba a los servicios públicos como aquellas actividades de titularidad estatal gestionadas en régimen de monopolio público ${ }^{9}$, se ha visto reflejada en la concepción que la misma Contraloría General de la República ha tenido sobre los servicios públicos, como destacan Pantoja y Camacho ${ }^{10}$. En su virtud, se configuró un servicio público de carácter orgánico-formal constituido por las organizaciones del Estado encargadas de satisfacer necesidades públicas de manera regular y continua, sujetos a la dependencia o supervigilancia del Presidente de la República, y dotados de un régimen de Derecho público. Lo mismo incluso fue recogido por el artículo 28 de la LOCBGAE que establece que:

Los servicios públicos son órganos administrativos encargados de satisfacer necesidades colectivas, de manera regular y continua. Estarán sometidos a la dependencia o supervigilancia del Presidente de la República a través de los respectivos Ministerios, cuyas políticas, planes y programas les corresponderá aplicar, sin perjuicio de lo dispuesto en los Artículos 22, inciso tercero, y 30.

La ley podrá, excepcionalmente, crear servicios públicos bajo la dependencia o supervigilancia directa del Presidente de la República.

En su virtud, se genera una tipología que es posible caracterizar como "cerrada" de servicios públicos, la que se funda en los artículos 29 a 33 de la misma LOCBGAE que permite diferenciar entre servicios públicos nacionales, regionales y municipales; centralizados y descentralizados; y servicios de gestión directa y de gestión indirecta (concesionados o convenidos).

\subsection{Caracterización fundamental del servicio público tradicional}

Conforme lo anterior, se reconocen como elementos de la noción tradicional, sin los cuales no era posible reconocer un servicio público en este sentido, los siguientes: una necesidad de interés general, la prestación del servicio por parte de la Administración Pública directa o indirectamente, y la existencia de un régimen jurídico especial respecto de dicha prestación (de Derecho público) ${ }^{11}$.

Luego, sobre la concepción tradicional -típicamente orgánica del servicio público como se ha dicho-, se construyó un régimen jurídico propio caracterizado especialmente del modo que sigue: en primer término, una titularidad pública sobre la actividad, que se traducía en la publificación o reserva estatal de la misma en favor de la Administración en general o de algún ente público personalizado. Como segunda característica, la existencia de poderes reservados de dirección, vigilancia y control sobre el servicio mismo a favor de

\footnotetext{
8 ARIÑo et al. (2004) p. 548.

9 De la Cuétara (1997 a) 112.

10 Pantoja Bauzá (1998) 99-101. También véase Camacho Cepeda (2010) 269-273.

11 Bermúdez Soto (2010) 160-161.
} 
la Administración; y consecuencialmente, la responsabilidad de la Administración sobre el servicio. En tercer lugar, continuidad y regularidad en la prestación, la igualdad de trato a los particulares/administrados y obligación de suministro como caracteres esenciales de todo servicio público. En cuarto lugar, una deslegalización y atribución a la Administración Pública de amplios poderes de regulación; la que se fundaba en una idea muy extendida de atribución general de poderes. En quinto término, una exigencia de previa concesión o título habilitante para ingresar en el sector, para el caso que se permitiera la participación de privados en ello por vía de gestión de un servicio determinado; lo que se completaba con la temporalidad de la concesión u otro título. Finalmente, como sexta característica, un régimen de tarifas o precios públicos o copago, cuando el servicio sea prestado directamente, sea que se haga por intermedio de particulares a quienes se ha otorgado un permiso, licencia o concesión para ello.

A partir de ello, se puede afirmar que este servicio público sirvió al paso desde una sociedad desequilibrada, rural, ineducada, sin salud, sin transportes, sin comunicaciones, a una con mayores grados de instrucción, más urbana, más igualitaria y con mayores grados de esperanza de vida. Por ello, el servicio público es merecedor de grandes elogios, pues fue un instrumento de enorme progreso y de socialización; y de este modo, la concepción legal plasmada en el artículo 28 de la LOCBGAE antes citado, se corresponde con la noción tradicional. Sin embargo, siempre pervive desde esta perspectiva la volubilidad de la noción en la medida que, como señala Jèze, para saber si existe servicio público o no en un caso habrá que estar a la intención de los gobernantes en lo relativo a la actividad administrativa de que se trate $^{12}$, por tanto esencialmente cambiante. De manera tal que bajo esta perspectiva serán servicios públicos los que los gobernantes en un lugar y tiempo determinado han resuelto satisfacer por medio del procedimiento y actividad de servicio público, que implica la existencia de un conjunto de reglas jurídicas especiales destinadas a facilitar el funcionamiento regular y continuo del mismo, para solucionar las necesidades del tipo, reglas que al mismo tiempo son susceptibles de modificación en todo instante para dar cabida a cada una de las necesidades de interés general que se intenta satisfacer. Por lo anterior, dicha concepción tradicional es criticada sustantivamente por Pantoja, en el sentido que se trata de un concepto restringido, y consiguientemente no completo, puesto que refiere solo a la organización básica de la Administración Pública, conformada por ministerios, intendencias, gobernaciones y servicios públicos stricto sensu; por consiguiente, nada dice acerca de los servicios públicos prestados a través de concesiones; y tampoco a las empresas públicas creadas por ley que tienen objetos prestacionales ${ }^{13}$. Todo ello lo hace, por tanto, muy deficitario.

Al mismo tiempo, dada esa misma volubilidad denunciada, unida a la ocupación de la totalidad del sector de la actividad, y a terminar haciendo en definitiva todo aquello que era capaz de hacer, se generó en la práctica una verdadera "patente de corso" a favor de los servicios públicos, lo que contribuyó al desenfreno de su actividad. Como consecuencia de ello muchos servicios públicos se hipertrofiaron rebajando los estándares técnicos de la actividad, en cuya virtud no fue extraño que varios de ellos se descapitalizaran financiera-

12 JÈZE (1928) pp. 289-290.

13 Pantoja (1998) pp. 378-379. 
mente, en tanto otros crearon infraestructura innecesaria, unos tantos fueron superados por la evolución tecnológica, y -en fin-el cobro por sus prestaciones o tarifas en algunos eran excesivas y en otros artificialmente bajas sin justificación.

A partir de lo expresado -que denota un fracaso o, a lo menos, una clara insuficiencia de ese modelo-, debe surgir necesariamente una nueva concepción sobre el mismo, que enseguida se pasa a revisar.

2. En lo QUe VIENe, El SERVICIO PÚblico SURGido LUEGO DE SU PROCESO DE PRIVATIZACIÓN O LIBERALIZACIÓN

\subsection{Evolución y antecedentes para una nueva conceptualización}

La concepción tradicional, cuyas características y elementos se han descrito de manera apretada, comienza a ser alterada por la realidad en la medida que particulares comienzan a prestar servicios públicos (de manera directa), otros servicios son prestados por sociedades estatales regidas enteramente por el Derecho privado (como sociedades anónimas de las que la Administración del Estado, o alguna de sus múltiples personificaciones es "accionista"), comienzan a realizarse actividades empresariales que no tienen que ver con satisfacción de necesidades colectivas (como empresas automotrices o de electrodomésticos), y los particulares comienzan a realizar actividades que -sin ser de interés general-se rigen por procedimientos de Derecho público; situaciones que no se adecuan ni responden a la tipología "oficial" descrita por la Contraloría General de la República ${ }^{14}$. De este modo, además de la volubilidad ya indicada en el acápite anterior, el servicio público empieza a tornarse difuso o incluso desarticulado si es que se piensa en lo que constituyen sus pilares estructurales.

Ante ello, cabe afirmar ahora que el servicio público precedentemente descrito y caracterizado, ya acabó su ciclo con la configuración que tenía. Y esto se avala, por el hecho cierto que a fines de la década de 1980 se asentó en el mundo y especialmente en Chile -apreciándose que este fenómeno tenía carácter global-, la convicción que el Estado se había hecho demasiado grande y su incapacidad era notoria, al mismo tiempo que la ineficiencia económica del sector público era alarmante, y la calidad de los servicios muy deficiente o mínima ${ }^{15}$, de manera que de servicio al público quedaba muy poco, habiendo sido reemplazado por el servicio a una burocracia temporal. En virtud de esta convicción, a lo que debe sumarse todo el nuevo panorama del ordenamiento jurídico chileno a partir de la CPR -que configuró un Estado subsidiario, democrático y de Derecho-, comenzó a cambiar al servicio público indefectiblemente.

En la especie, a partir de dicha década se inicia un proceso de privatización o liberalización de los servicios públicos, antes monopolizadas por el Estado (con publificación de la actividad incluida, como se había destacado); los que ahora comienzan a considerarse actividades libres pero reguladas, ampliándose de este modo la esfera de actuación económica de los particulares. Especialmente en Chile se realizó una privatización "a la inglesa”,

14 Camacho (2010) p. 271.

15 Ariño et al. (2004) p. 600. 
aprovechando al máximo el capital e impulso privados, y reduciendo de paso el estatismo excesivo $^{16}$.

A mayor abundamiento, en este panorama aparece la referencia a nivel constitucional con los servicios de utilidad pública, específicamente en el artículo $19 \mathrm{~N}^{\circ} 16$ inciso 6 de la CPR, que concretamente refiere a aquellas actividades donde se reserva una titularidad pública de la actividad o solo de algunos sectores de ella en cuyo caso será necesario obtener la concesión respectiva, mientras que en los demás aspectos de la actividad se implementan técnicas de supervigilancia e informe habitualmente, lo que en términos estrictos es únicamente la vieja policía administrativa o en términos modernos la actividad de ordenación; en cuyo caso la regulación de las actividades correspondientes a dichos servicios impone obligaciones o cargas de servicio público, con el objeto de garantizar que la actividad se preste bajo condiciones predeterminadas de calidad, precio o tarifa y en igualdad de acceso a los usuarios. Esto ocurre así en la Ley General de Telecomunicaciones, en la Ley General de Servicios Sanitarios y en la Ley General de Servicios Eléctricos ${ }^{17}$.

Por último, la CPR aparte de delinear el Estado suplente o subsidiario con la configuración ya vista, establece un límite claro - "una valla" dice Camacho ${ }^{18}$ - a su actividad económica, prohibiéndole en general su realización, salvo que se le autorice expresa y determinadamente (con giro específico incluido) en virtud de una ley de quórum calificado. En este sentido quisiera destacar que uno de los clásicos del Derecho Administrativo chileno, como es Silva Cimma, señala en su tan conocida obra que "hasta hace poco tiempo, creíamos que en el Derecho Administrativo chileno solo era posible pensar, al referirse al servicio público, en una concepción única y exclusivamente orgánica (...) hoy en día, y después de profundas meditaciones sobre el tema, nos parece que tal aserto no puede ser tan categórico y se nos hace tarea mucho más difícil la de intentar una definición única del servicio público chileno (...)”19. Y más adelante continúa afirmando, que si bien normativamente o de modo general se usa mucho en nuestro país la expresión servicio público desde un punto de vista orgánico, "se abre paso paulatinamente, pero en forma definitiva, el imperio de la concepción funcional"20.

Sin perjuicio de ello, la verdad es que sea utilizando la noción orgánica ${ }^{21}$-que lo define como los órganos o entes que integran la Administración de un Estado y a la actividad que tales órganos realiza, cualquiera que ella sea-, sea que se utilice la concepción funcional $^{22}$-que lo define como una actividad que persigue un fin de interés general, bien que sea ella realizada por una entidad o cuerpo estatal, bien por personas privadas, sean jurídicas o naturales-; lo cierto es que cualquiera de esas dos nociones finalmente tradicionales del servicio público, resultan insuficientes a la luz de lo establecido actualmente en el

\footnotetext{
16 De la Cuétara (1997 a) p. 119. Allí se destaca que países como Chile han asumido esta fórmula con éxito.

17 СамасHо (2010) pp. 274-275.

18 Camacho (2010) p. 284.

19 Silva Cimma (1995) pp. 47-48.

20 Silva Cimma (1995) p. 51.

21 Silva Cimma (1995) p. 27.

22 Silva Cimma (1995) p. 28.
} 
panorama jurídico chileno, en especial considerando el marco de lo que comúnmente se denominó la "Constitución económica"23.

\subsection{Replanteamiento de la noción}

Por todo lo dicho, se hace necesario un nuevo concepto del servicio público -realista si se quiere-, del que emanen nuevos efectos, por las proyecciones e importancia que ello tiene en la vida cotidiana de los particulares, titulares de derechos subjetivos públicos, y que precisamente son los usuarios de dichos servicios. Y ese concepto, necesariamente amplio, debe atender a la teleología de la actividad: satisfacer necesidades públicas; por consiguiente, parece que debe vincularse antes que con el órgano, con la cobertura de dichas necesidades. De manera coincidente, en este trabajo se propone considerar a los servicios públicos desde una perspectiva esencialmente funcional, en el sentido que ya no se debe atender de manera principal al sujeto que realiza la actividad a quien tradicionalmente se le imputaba la titularidad en carácter monopólico de esta actividad prestacional -y era centro de la construcción normativa-, sino que desde aquella que atiende o centra su atención en la actividad misma.

$\mathrm{Al}$ respecto cabe atraer lo señalado por Braconnier, cuando identificando los elementos materiales y caracterizando el servicio público, destaca como tales los siguientes: a) una actividad de interés general; y b) la sumisión de la misma a un régimen exorbitante del Derecho privado ${ }^{24}$.

En la especie y para esta investigación, estos factores constituyen un elemento fundamental para la identificación del servicio público desde la perspectiva que se está utilizando, claramente material antes que ligada a la identificación de una persona pública que lo preste. Con ello, se deja de lado, evidentemente, una concepción que centra su atención en las personalidad de quien actúa para recentrar esa mirada en la actividad misma y en el régimen jurídico habilitante.

No se quiere, sin embargo, esquivar quién realiza la actividad sino que se quiere colocar esa cuestión en su justo término. Al respecto, señala certeramente Muñoz Machado que una vez afirmado que el servicio público ha perdido su carácter predominantemente orgánico, lo que sí puede decirse claramente del mismo es que hoy se trata y es posible sostener una noción más bien material que se refiere a actividades gestionadas en condiciones jurídicas exorbitantes del Derecho común -de los particulares-, realizadas tanto por las administraciones públicas como por los privados ${ }^{25}$. Y de manera especialmente relevante a esta investigación es la cuestión destacada por él mismo, en el sentido que ya no solo existen servicios públicos calificados formalmente como tales que no se atribuyen a las administraciones públicas, sino que en otras oportunidades las prerrogativas y posiciones exorbitantes al Derecho común de estos, no se justifican porque las hayan recibido de un

\footnotetext{
23 A partir, fundamentalmente, del artículo 19 numerales 21 a 25 de la CPR.

24 BraconNier (2003) pp. 156-174.

25 Muñoz Machado (1997) p. 318.
} 
acuerdo contractual o concesional con la Administración concedente, sino que mediante una atribución directamente derivada de la ley ${ }^{26}$.

Conectando con esto, se entiende y justifica más plenamente una concepción más compleja de entendimiento de los fenómenos fácticos y jurídicos asociados al Derecho Administrativo - conocida como concepción dual o bifronte- en donde por un lado se reconocen a las Administraciones Públicas personificadas en sí mismas como una estructura organizativa independizada, precisamente para actuar en régimen de Derecho Administrativo (o, lo que es lo mismo, organizaciones que no gozan de otro poder del Estado que el juridificado en forma de potestades administrativas, por lo que en ellas puede partirse de la idea del Derecho Administrativo como ordenamiento común y normal, siendo el deslinde conceptual básico que debe hacerse de frente al Derecho privado); y, por otro, se reconoce también en las corporaciones y organismos de Derecho público o privado en que confluyen diversos órdenes jurídicos, debiendo separarse lo que es potestad administrativa de lo que no. Consecuencialmente, ahora ya no es correspondiente o necesario, el servicio público con la titularidad estatal.

Enseguida, como bien se sabe, hoy el servicio público expansivo y con fuerte vinculación a la satisfacción de necesidades generales de la población -mínimas si se quiere y ligadas a la electricidad, agua potable, gas, telefonía entre otros-, es prestada mayoritariamente por un mercado regulado bajo nuevos paradigmas surgidos del desarrollo del "orden público económico" trazado a partir de la reconfiguración de los mismos desde la CPR, promoviendo la competencia allí donde sea posible o simulándola en su caso, para proteger los intereses de los usuarios en los casos en que se mantengan situaciones monopólicas o cuasi monopólicas ${ }^{27}$. De modo tal que si en el modelo clásico de regulación de los grandes servicios ya referidos, el ente administrativo asumía la mayoría de las decisiones vinculadas a la planificación, inversión, financiación, precios, optimización, explotación hasta llegar a detalles muy específicos -todo ello ligado a la idea de cobertura total de la actividad o sector-ligados a la prestación misma; ahora con el nuevo modelo de regulación, en general se ha separado al regulador del prestador y en su virtud se utilizan los modos de la competencia, como ocurre con el agua potable y alcantarillado o en la telefonía ${ }^{28}$. De este modo, la competencia es el objetivo prioritario y la regulación es el instrumento jurídico necesario para defenderla, para crearla cuando aquella no existe, o para sustituirla cuando sea imposible su creación porque existan elementos de monopolio natural u oligopolio involucrados ${ }^{29}$; debiendo señalar que en cualquier caso, a los particulares que prestan estos servicios se les impone un verdadero régimen exorbitante, que se traduce en obligaciones o cargas de servicio público, consistentes en general en el respeto por las reglas de funcionamiento de los mismos.

Esta idea es definitivamente coincidente con el cambio de giro experimentado por todo el ordenamiento jurídico chileno a partir de la CPR que consagra la subsidiariedad o

\footnotetext{
26 Muñoz Machado (1997) pp. 318-319.

27 Vergara Blanco (2004) pp. 33-49.

28 Ariño et al. (2004) p. 604.

29 Como ocurre, por ejemplo, con los abastecimientos de telefonía, electricidad y más aun en los servicios sanitarios. Véase ARIÑo et al. (2004) p. 606.
} 
supletoriedad general en el ámbito económico, pasando de la servicialidad asistencialista de la Administración Estatal a la libertad de empresa, y en los casos de servicios públicos destacados, la regulación -como instrumento normativo- será siempre necesaria, pero en principio debe ser solo la necesaria, imprescindible, subsidiaria y complementaria del mercado.

Así, el nuevo servicio público -el de hoy- resulta que debe ser entendido sobre la base de tres postulados mínimos, como son: su juridificación, reemplazando la discrecionalidad por fórmulas de fiabilidad y previsibilidad a partir de su marco jurídico; su necesario redimensionamiento, de manera que la universalización tenga un correlato en la organización de los medios para que pueda ser satisfecha efectivamente y la igualdad se concrete en prestaciones de base o mínimas que se garanticen para todos, descargándose del exceso de tareas; y como resultado de lo anterior, la concreción de una prestación básica universal, ofrecida a los ciudadanos y garantizada por el Poder Ejecutivo ${ }^{30}$. Ante este panorama, solo cabe añadir que en este contexto no resulta extraña la constatación que hoy los particulares prestan servicios públicos que se encuentran regulados plenamente, constituyendo una situación o forma de servicios dirigidos a la satisfacción de necesidades generales del público, por medio de actividades privadas realizadas en interés general por estos, lo que tiene un claro sustento normativo en el artículo 19 No 10 inciso final, No 16 inciso final y 63 No 10 de la CPR ${ }^{31}$.

Resulta particularmente paradigmático de lo dicho, lo que sucede en la actividad pública de inspección y de control de riesgos -una policía administrativa moderna y de configuración reciente-, que se realiza y concreta en muchos sectores por entidades claramente privadas y colaboradoras permanentes u ordinarias de la Administración, los que operan con medios técnicos y personal especializado, constituyendo un genuino ejercicio de funciones públicas por particulares, que adoptan resoluciones dentro de procedimientos de naturaleza administrativa y dictando actos de idéntico carácter ${ }^{32}$. Y si se trata de ejemplos concretos, esto tiene una especial aplicación en el caso de la certificación ambiental, al remitir la Administración Pública a entidades privadas la competencia técnica, independencia e idoneidad moral con el fin de que ellas den fe del cumplimiento de los requisitos o condiciones ambientales de un producto, proceso o establecimiento ${ }^{33}$.

\section{CONFIGURACIÓN ACTUAL DE LOS SERVICIOS PÚBLICOS}

Ante esta realidad -la evidencia es abrumadora-, se afirma sin duda alguna que se han reconfigurado los servicios públicos a partir de una reconducción y purificación del concepto a lo que le es propio, descargando esta actividad del pesado lastre que colocaba su acento en la organicidad. Es en este momento en donde debe dejarse constancia que esas actividades de servicio público en sentido amplio, deben atender a satisfacer necesidades públicas o colectivas - como no puede ser de otro modo-, pues la misma CPR define teleo-

\footnotetext{
30 De la Cuétara (1997 a) pp. 132-167.

31 Pantoja (1998) pp. 266-267 y 337.

32 Esteve Pardo (2011) pp. 370-371.

33 Bermúdez (2007) pp. 217-218. También véase Esteve (2008) pp. 153-155.
} 
lógicamente nuestro Estado como servicial, democrático y de Derecho ${ }^{34}$. De esta manera la noción actualizada de servicio público, en cuanto fenómeno material y jurídico, es más bien un Derecho de regulación de actividades económicas donde están involucrados intereses generales o colectivos -o sea, de toda la población o de alguna parte de ella-y en definitiva públicos, identificando la noción de servicio público con una técnica legal de regulación sobre actividades de contenido económico cuya titularidad ostenta la Administración pública o no, y su gestión es realizada fundamentalmente por particulares, destinadas a la satisfacción de necesidades generales o sectoriales y colectivas ${ }^{35}$.

Dada la privatización o liberalización de los servicios públicos de régimen prestacional de titularidad estatalizada y, por consiguiente, perdida esa posición surge como alternativa a ella un régimen de regulación de servicios públicos, en especial los caracterizados como servicios económicos de interés general; cambiándose el eje central desde la titularidad estatalizada a la del régimen jurídico, constituyéndose un verdadero Derecho de la regulación de actividades económicas -como se dijo anteriormente-, que desplaza el régimen de actividad administrativa de prestación, y que debe atender intereses de toda la población ${ }^{36}$; lo que ha generado la recepción en Europa continental, en gran parte de Iberoamérica así como en Chile de este modelo de regulación, tras la pérdida de posiciones de dominio y titularidad en toda una serie de sectores económicos, los que de todas maneras mantienen su marcada presencia e interés públicos ${ }^{37}$. En este sentido, esta actividad es fundamento y explicación, ya no del Estado de Policía ni Estado del Bienestar, sino de un Estado garante $^{38}$ de intereses públicos frente a la actividad de empresas privadas que funcionan en régimen de mercado y competencia en aquellos sectores que tienen relevancia para la sociedad y sus habitantes, que habitualmente se corresponden con servicios esenciales para la población, y garantizando que en ellos se realicen prestaciones básicas conforme reglas o principios mínimos de operación ${ }^{39}$.

Dicho lo anterior, que sirve para explicar sucintamente este panorama; para los efectos propios de esta investigación es preciso trazar de todas maneras una clasificación, por general que sea, con el fin de tomar uno de estos tipos que se indicarán y desarrollarlo. Así, tomando como base lo explicado por Camacho ${ }^{40}$ y agregando uno más, es posible distinguir entre:

a) los servicios públicos estatales propiamente tales (o de prestación directa), suministrados por un órgano integrante de la Administración Pública titular del servicio, por un órgano no diferenciado pero con competencia exclusiva, por una entidad descentralizada y autónoma de tipo fundacional, o incluso por una empresa -pública o privada-del Estado constituida al efecto;

\footnotetext{
34 Artículos 1 inciso $4^{\circ}, 4,6$ y 7 CPR.

35 Tomo como base a Nallar Dera (2010) pp. 163-166.

36 Esteve Pardo (2011) pp. 465-466.

37 Esteve Pardo (2010) pp. 298-299.

38 El Gewähleistungstaat en Alemania.

39 Esteve Pardo (2011) p. 466. Coincide en ello Rodríguez-Arana (2012) p. 206.

40 Camacho (2010) pp. 289-294.
} 
b) los servicios públicos concedidos (o de prestación indirecta), en virtud de convenios, contratos específicos, concesión de explotación de servicio público, y concesión de actividades cuasi publificadas también denominada concesión de servicio público (en sentido funcional); y

c) los servicios de utilidad pública (o de mercados regulados), como sería el caso de las telecomunicaciones y telefonía, agua potable y servicios sanitarios, y electricidad.

Luego, a efectos de esta investigación, será pertinente desarrollar una categoría que hasta ahora no se había tratado con detención en nuestro país o solo sido había referida de manera tangencial, y que típicamente se indica como una figura intermedia, ubicada a medio camino entre una actividad libre y un servicio público. Se trata de los servicios públicos virtuales o servicios públicos impropios o mejor aun servicios privados de interés público (SPIP), que enseguida se pasarán a analizar con mayor detención, pues ahora se atenderá resumidamente lo relativo a los principios o, más propiamente, reglas de funcionamiento de los servicios públicos.

Finalmente, antes de encarar lo siguiente, conviene aclarar que no cualquier servicio al público puede recibir una cualquiera de las denominaciones anteriores, e incluso la última de ellas -los SPIP objeto de este trabajo-, sino que solo aquellos que o son titulares de potestades administrativas configuradas legalmente, o que soportan cargas públicas con igual configuración ${ }^{41}$; lo que resuelta ser una consecuencia de la pérdida de posiciones de titularidad estatal, que ha sido reemplazada por la toma de posición garantista a que se ha aludido anteriormente por parte de la Administración Pública ${ }^{42}$.

\section{LUEGO, LOS PRINCIPIOS Y REGLAS DE PRESTACIÓN DE LOS SERVICIOS PÚBLICOS}

De acuerdo a lo visto, a fin de seguir avanzando es preciso realizar un desarrollo -esquemático que sea- acerca de los principios o reglas generales de funcionamiento de los servicios públicos lato sensu, lo que resulta aplicable a cualquiera de las tipologías señaladas, cuestión que pasa a realizarse ${ }^{43}$. Los dos primeros atienden a responder ante la necesaria confiabilidad en ellos por parte de la sociedad; y los dos siguientes a responder por la forma o modo en que se prestan precisamente.

\subsection{Universalidad}

También denominado principio de generalidad, con el que fundamentalmente se alude a la accesibilidad general a actividades prestacionales de bienes y servicios que por su carácter vital o básico han de ofrecerse al conjunto de las personas, quienes deben recibir el servicios en condiciones de accesibilidad general sin perjuicio que por ello se pague una tarifa.

Ello implica que los servicios deben resultar asequibles a todas las personas con independencia de sus condiciones y situaciones específicas ${ }^{44}$, o adecuándose a ellas en su caso,

\footnotetext{
41 Así se excluyen, en principio, todas las instituciones de beneficencia privada.

42 Esteve (2012) pp. 20-24.

43 Se explican tomando como base a Zegarra Valdivia (2005) pp. 59-60.

44 Esteve (2011) p. 435.
} 
a objeto de concretar su utilización y prestación del servicio conforme las normas legales y reglamentarias que lo regulen. En especial el acceso, debe garantizarse en condiciones semejantes de calidad a todos los usuarios y con las mismas garantías de atención ${ }^{45}$.

Sobre ella, se ha dicho que, antes que principio, hoy es una regla técnica que vino a reemplazar el servicio público de titularidad estatal exclusiva, para conseguir ahora en un área despublificada pero regulada una de las notas del servicio público, cual es la universalidad de ciertas prestaciones ${ }^{46}$.

\subsection{Continuidad}

Constituye el primer principio -sin el cual no se puede concebir cualquier servicio público-, y expresa la exigencia del funcionamiento ininterrumpido del servicio en las condiciones adecuadas a la población a la que se le presta.

Sobre ella, se ha sostenido su esencialidad al señalar que "el concepto de servicio público, por ser servicio, ha de consistir en la actividad prestada continua y regularmente por una organización” ${ }^{47}$. Al mismo tiempo, debe ser entendida como la base sobre la cual se sustenta la prestación, y se funda en que una determinada actividad que ha recibido dicha consideración se encuentra a disposición de los usuarios de forma permanente, o como expresa Villar Palasí "se configura como esencial al servicio público la prestación regular y continua" ${ }^{38}$, y comprende distintas aplicaciones dependiendo de la naturaleza del servicio, como pueden ser la uniformidad horaria, o la disponibilidad permanente del servicio -sus medios y personal correspondiente- para satisfacer aquellas necesidades que pudieran surgir en el sector o parcela de sector que es atendido por este. Ello, sin embargo, no implica que en todos los casos deba prestarse siempre materialmente, sino que lo requerido es que sea proporcionada cada vez que aparezca la necesidad y se le requiera; de manera tal que lo que sí se exige son unas garantías precisas para asegurar el funcionamiento del servicio ${ }^{49}$. Al mismo tiempo, se impone al titular-prestador del servicio público la obligación de asegurar que el suministro no será interrumpido, salvo causas de fuerza mayor que le dejen en una situación de imposibilidad de continuar la prestación del servicio ${ }^{50}$.

Esta continuidad se protege, tradicionalmente, de modo general por dos formas o maneras $^{51}$ :

- por la posibilidad que la Administración, en casos excepcionales o de urgencia, proceda a la ejecución directa del servicio cuando este sea prestado por los particulares; $y$

- en la prohibición o restricción del derecho a huelga.

45 Camacho (2007) pp. 471-472. También véase Fernández García (2003) p. 429.

46 Fernández García (2003) p. 420.

47 De la Cuétara (1983) pp. 126-127.

48 Villar Palasí (1964) p. 160.

49 Fernández García (2003) p. 433.

50 Incluso en algunas áreas, aquello tampoco constituye fundamento de excepción, como ocurre en alguna medida en el ámbito de la industria energética.

51 Cassagne (2002) p. 304. 
En este último punto, conviene apuntar que acá surge claramente un conflicto con el derecho a huelga de los trabajadores de los servicios, lo que en algunos casos se salva por el establecimiento de un sistema de atenciones mínimas, que en cada sector se formaliza a través del reconocimiento y condiciones que se concretan en los convenios colectivos que suscriben $^{52}$. No obstante en nuestro Derecho ello tiene una fisonomía un tanto difusa y más bien balanceada del lado de los usuarios antes que de los trabajadores de dichos servicios, toda vez que en el artículo 19 No 16 de la CPR se contempla efectivamente una restricción al derecho a huelga de los trabajadores o funcionarios del Estado y de las municipalidades, agregándose más adelante en el mismo numeral a "las personas que trabajen en corporaciones o empresas, cualquiera que sea su naturaleza, finalidad o función, que atiendan servicios de utilidad pública o cuya paralización cause grave daño a la salud, la economía del país, al abastecimiento de la población o la seguridad nacional"; y dicha disposición se complementa con el artículo 84 letra i) del Estatuto Administrativo y con el artículo 384 del Código del Trabajo que repiten y completan la norma constitucional indicada, situación que en todo caso conserva vacíos y desregulación, cuestión que ya se ha analizado y afirmado anteriormente en concreto ${ }^{53}$, lo que debería enmendarse disminuyendo -siempre a favor de los usuarios- la discrecionalidad rayana en arbitrariedad e incerteza -conforme las prescripciones normativas citadas-, inadmisible en un Estado de Derecho, aumentando con ello la confianza en el sistema para todos sus actores.

\subsection{Igualdad y no discriminación}

Conecta con el anterior principio, y constituye una manifestación del principio y derecho de igualdad general, consagrado constitucionalmente en el artículo $1^{\circ}$ y 19 No 2 $\mathrm{CPR}$, en cuya virtud se sanciona consecuencialmente la interdicción de la arbitrariedad.

En el caso de esta regla aplicable específicamente para los servicios públicos, se obliga al prestador a tratar de la misma manera a las personas que se encuentren en una misma situación de hecho o de Derecho ${ }^{54}$. Lo que tiene el efecto de proscribir e impedir cualquier factor de discriminación arbitraria -es decir, basados en el mero voluntarismo- en el acceso y utilización de los servicios; surgiendo de este modo un verdadero derecho subjetivo público de acceso y disfrute del servicio en condiciones paritarias a todos aquellos a los que va dirigido.

Se trata de una igualdad de todos los ciudadanos beneficiarios, en el acceso a las prestaciones que comprende, sin que exista la posibilidad de poder negarse a alguien en la medida que las capacidades y posibilidades del servicio lo permitan ${ }^{55}$. Ello genera como efecto, una prohibición de trato discriminatorio, tanto en el acceso al servicio como en las condiciones y modalidades de su prestación.

\footnotetext{
52 Esteve (2011) p. 435.

53 Zúniga Urbina / Sepúlveda Rodríguez (2010) pp. 406-419. También véase Cazor Aliste / Cortés Moreno (2012) pp. 253-255.

54 Zegarra (2005) p. 60.

55 Fernández García (2003) p. 436.
} 


\subsection{Mutabilidad}

También conocida como adaptación al progreso técnico, lo que exige que el servicio responda en todo momento en sus características materiales a un óptimo nivel de satisfacción del interés general, e implica que las prestaciones suministradas al público han de estar siempre adaptadas a sus necesidades ${ }^{56}$. Este principio y regla tiene un marcado carácter técnico -en contraposición a otros, como el de igualdad, sustancialmente político-, aunque de todas maneras y en último término se vincula con la satisfacción del interés público o general.

En particular puede señalarse sobre el mismo que, en virtud del proceso de privatización o liberalización, se ha roto el vínculo entre el servicio y la prestación pública por el servicio, sea porque este ya no existe, sea porque se ha transformado en regulador en un régimen de libre iniciativa empresarial en su prestación. De lo anterior, resulta más bien una serie de técnicas destinadas a garantizar el efectivo respeto de este principio por los operadores privados; y en todo caso debe establecerse una correlación entre la adaptación al progreso técnico y la garantía de calidad en la prestación.

\section{EN PARTICULAR, LOS SERVICIOS PRIVADOS DE INTERÉS PÚBLICO (SPIP)}

\subsection{Explicación general sobre la categoría}

Cabe señalar desde ya que es intención de este estudio, resolver la aplicación al caso en estudio de esta discutida categoría -la ya referida de los servicios públicos virtuales o impropios o, como se considera mejor denominarlos, servicios privados de interés público-, la que se explica brevemente a continuación.

Con esta denominación se conoce a determinadas actividades que no han recibido una publificación expresa, pero que son objeto de una intensa regulación interventora de la Administración Pública correspondiente, en cuanto existe en ellas un interés público que se considera debe ser tutelado ${ }^{57}$, pues aunque son "servicios privados", están dotados de una relevancia que trasciende los términos estrictos del interés particular ${ }^{58}$ donde solo se encuentran en juego derechos subjetivos privados, y por ello se justifica su dimensión pública. Se trata de actividades claramente servidas por particulares las que, al mismo tiempo, son fuertemente intervenidas en razón del hecho que las cuestiones a que se refieren las mismas y que se traducen en un bien o en un servicio, no tienen un interés meramente particular, sino que se excede dicho ámbito, encontrándose comprometido con ello un interés general o colectivo -público finalmente-, con lo que realizan.

Así es posible señalar que cuando se habla de servicios públicos impropios o servicios públicos virtuales o, mejor aun, de servicios privados de interés público (SPIP), se hace referencia a actividades que, sin estar reservadas expresamente a la acción estatal ni calificadas como actividades de servicio público, no pueden desarrollarse en un régimen puro de libertad económica y jurídica, puesto que tienden a la satisfacción de intereses generales -públicos- o colectivos -de algún grupo determinado- donde, sin embargo, su titularidad

\footnotetext{
56 Fernández García (2003) p. 442.

57 Sendín (2003) p. 118.

58 Entrena Cuesta (1958) p. 40.
} 
y responsabilidad no corresponde a las Administraciones Públicas. En estos la Administración Pública se reserva habitualmente poderes de intervención y control que van más allá de la mera autorización inicial, conservando poderes de ordenación a lo largo del ejercicio de la actividad 59 .

Las condiciones que derivan de dicha calificación, que normalmente no es legal sino solo doctrinal, recaen en la imposición de obligaciones o cargas de servicio público, que se traducen normalmente en la imposición a los suministradores u operadores privados de ciertas actividades, a realizar la prestación de forma que los intereses públicos y colectivos continúen siendo protegidos y satisfechos. Hay en ellos, una habitual relación de sujeción, en cuya virtud existe el deber de hacer o de prestar -sin concesión previa-, lo que proyecta y concreta una situación jurídica general objetivada por el ordenamiento ${ }^{60}$. Se adiciona, siguiendo ahora a Sarmiento en torno a esta distinción, que si el servicio propio es aquel que es prestado o satisfecho directamente por parte de la Administración del Estado, mientras que el impropio es un servicio destinado a la satisfacción de necesidades colectivas en forma más o menos continua, pero que solo es reglamentado por el Estado, sin que este lo preste o conceda. Se trata, claro está, de actividades realizadas por los particulares por medio de las cuales se satisfacen necesidades públicas o colectivas, por lo que se establece una regulación claramente más intensa determinando la forma como deberá ser ejercida la actividad, imponiendo condiciones técnicas, efectuando fiscalizaciones entre otras cuestiones ${ }^{61}$; lo que justifica claramente la inclinación de la balanza hacia la regulación como método de intervención estatal de ello y en donde sí aparece dicha organización jerarquizada.

En consecuencia, dadas las diferencias con el servicio público tradicional, es preferible terminológicamente no usar aquella, aunque posteriormente se le añada virtual o impropio, sino preferir la de SPIP. De todas maneras, cabe señalar que para realizar dicha calificación, hay que atender a las características específicas del caso concreto, pues no se puede aplicar sin más esta categoría a todos los casos de servicios compartidos o colaborativos. Se trata, específicamente, de actividades privadas que por su elevada repercusión sobre la vida colectiva, se someten a una ordenación detallada y minuciosa, con una intervención muy intensa de poderes jurídico-administrativos sobre ellas ${ }^{62}$. En otras palabras, en ellas no existe una declaración formal de servicio público -y tampoco lo son stricto sensu-, ocurriendo de todos modos que la Administración del Estado por razones de interés público se reserva poderes de intervención a partir de la existencia de un régimen especial de tipo legal o reglamentario. En este caso, no hay una declaración legal de titularidad pública sobre la actividad, sino que en definitiva se está presencia de un supuesto de una "actividad privada sujeta a una ordenación de policía especialmente intensa"63.

Han sido reconocidos como típicos ejemplos de esto el servicio de taxis, la actividad bancaria y la de seguros, la actividad farmacéutica, las actividades sanitarias o asistenciales

\footnotetext{
59 ARIÑo et al. (2004) p. 556.

60 AriÑo et al. (2004) p. 559.

61 Sarmiento García (1994) pp. 9-10.

62 De la Cuétara (1983) p. 227.

63 Fernández García (2003) pp. 125-126.
} 
privadas, y los centros privados de enseñanza. En estos casos estamos ante distintas situaciones que requieran autorización o no, o en otros casos una importante intervención por la vía del control de sus actos, y en ambas situaciones con una relación permanente de sujeción. En nuestra doctrina -escasa en este, como en otros aspectos-, solo Silva Cimma se refiere a la noción en dos sentidos: en oposición al servicio público propio, refiriéndose a la expresión "impropio" negando atributos de servicio público a este último caso; y por oposición al servicio público orgánico, con la expresión "virtual" conectando dicha figura -en mi parecer, de manera errada-con la concesión de servicios públicos. En todo caso, en ambas situaciones se trata de una categoría que no le atrae y le parece muy sutil ${ }^{64}$.

Sin embargo, estimo que por la fuerza de los hechos y atendiendo una vez más a la realidad, hoy resulta imposible negarla, especialmente dada la reconfiguración de los servicios públicos; y -coincidiendo con Sendín ${ }^{65}$-, solo si se considera como un supuesto imbatible la titularidad administrativa (y el monopolio de iure) del servicio público, es admisible negar la existencia de esta categoría, por muy híbrida que aparezca o por muy clara actividad de policía que sea, pues más bien esta última es un conjunto de técnicas ${ }^{66}$.

\subsection{En este contexto, interés público o general versus libre prestación de servicios}

Como elemento que contribuye a dotar de sentido la vinculación normativa del Derecho Administrativo a los SPIP, resulta ineludible referirse siquiera en términos generales o instrumentales a la noción de interés público o general, como elemento de atribución.

Aclaro que no es esta la ocasión para tratar en profundidad el concepto de interés público $-\mathrm{u}$ otros tan importantes como aquel, v. gr. bien común-, pues sería inevitable terminar en la Filosofía, buscando el sentido último de sus significancias. Sin perjuicio de lo anterior, y tratando esta temática en general y no respecto de un caso particular, se ha sostenido que los intereses públicos o generales son indefinidos, en cuanto ninguna norma lo hace, e indefinibles objetivamente, pues cumplen una función de cobertura legitimadora del contenido de las decisiones o intervenciones de los poderes públicos para un momento y lugar ${ }^{67}$. No obstante, dado el principio y regla de juridicidad en la actuación de la Administración Pública, lo que se concreta en la condición de ejercicio de sus potestades administrativas -en donde debe haber una finalidad objetivizada de ellas en la legalidad en sentido amplio, concurriendo en caso de duda el Juez-, se debe tender a producir una conceptualización dogmática del interés general dentro de la juridicidad administrativa ${ }^{68}$; aunque de todas maneras existe en ello el peligro del decisionismo o activismo judicial ${ }^{69}$.

Acá, sin embargo, se atrae este tema por la finalidad instrumental y atributiva, lo que permite tratar este punto muy sucintamente por lo demás.

\footnotetext{
64 Silva Cimma (1995) pp. 42-44.

65 SENDín (2003) p. 121.

66 Al respecto, señala Lachaume que el servicio público es la prestación, y la policía administrativa es la prescripción, por lo que las dos nociones no se excluyen. Véase Lachaume (1989) p. 25.

67 NieTo (1991) p. 2251.

68 Nieto (1991) p. 2252-2253.

69 Un análisis crítico de ello puede verse en CORdero VeGa (2012) s/p.
} 
Dicho lo anterior, conviene sostener que en el sentido dicho hay referencias al interés público o su sinónimo de interés general de una actividad o servicio -distinto del interés colectivo, es decir de un grupo-, tratándose de las necesidades que se quieren atender sin prejuzgar el modo en que debe servirse, pues ello no implica titularidad ni monopolio ni financiación estatales. Por otro lado, igualmente resulta usual construir la noción por exclusión u oposición a las actividades o servicios privados, por la consideración a la trascendencia pública que lleva a su regulación, más allá de las fuerzas puramente de mercado que participen en ello ${ }^{70}$. En este sentido, parece que la trascendencia social, de la actividad sobre la que recae es clave y fundamento de la intervención administrativa o control público, lo que admite distintas graduaciones que ponen en tensión el régimen de los servicios públicos lato sensu. A partir de ello se reconocen como técnicas interventoras en el servicio público la estatización en un lado (con nacionalización de actividades, supresión de títulos privados, monopolio público, gestión directa, etc.); la mera actividad de policía, en el otro (con declaraciones obligatorias, autorizaciones, licencias, órdenes, prohibiciones, inspecciones y sanciones); y la regulación económica, equidistante de ambos donde se conjugan técnicas de policía con otras como la libre competencia, la ordenación sectorial, disciplina de sectores específicos, relaciones de sujeción, las obligaciones y cargas de servicio público, entre varias más ${ }^{71}$.

En fin y a mayor abundamiento, conforme la CPR hay un atisbo general de ítemes que pueden constituir la base de un interés público o general normativizado y que colabora con esta determinación, en la medida que la libre prestación de servicios -entregada simple y puramente a las "reglas" de mercado-, solo puede limitarse justificadamente en razones de orden público, seguridad y salubridad públicas (inciso $4^{\circ}$ del artículo $1 \mathrm{CPR}$ ), la educación y la libertad de enseñanza ( ${ }^{o s} 10$ y 11 del artículo 19 CPR), la preservación de la libertad de empresa y la libre competencia previniendo los abusos (No 21 del artículo $19 \mathrm{CPR}$ ), u otros que tasadamente sean determinados por el ordenamiento jurídico ${ }^{72}$ o, en último término, por las decisiones que emanen de la jurisprudencia. Al respecto, son particularmente importantes los artículos 1, 6 y 7 de la CPR, repetidos en términos más o menos similares en los artículos 2 y 3 de la LOCBGAE, conforme los cuales los órganos de la Administración del Estado someterán su acción a la Constitución y a las leyes, deben actuar dentro de su competencia y no tendrán más atribuciones que las que expresamente les haya conferido el ordenamiento jurídico; siendo la finalidad de la Administración Pública la promoción del bien común atendiendo las necesidades públicas en forma continua y permanente y fomentando el desarrollo del país a través del ejercicio de las atribuciones que le confiere la Constitución y la ley, y de la aprobación, ejecución y control de políticas, planes, programas y acciones de alcance nacional, regional y comunal, debiendo observar en todo ello los principios de responsabilidad, eficiencia, eficacia, coordinación, impulsión de oficio del procedimiento, impugnabilidad de los actos administrativos, control, probidad, transparencia y publicidad administrativas, y garantizará la debida autonomía de los

\footnotetext{
70 Linotte/Mestre (1982) p. 49. También véase Villar Rojas (2004) p. 381.

71 De la Cuétara (1997 b) pp. 88-94.

72 Villar Rojas (2004) pp. 380-382.
} 
grupos intermedios de la sociedad para cumplir sus propios fines específicos, respetando el derecho de las personas para realizar cualquier actividad económica, en conformidad con la Constitución Política y las leyes ${ }^{73}$.

\subsection{Características principales}

Siguiendo a Cassagne en esto ${ }^{74}$, hay que señalar que esta categoría permite extender de modo excepcional el régimen jurídico de los servicios públicos a actividades que prestan los particulares, cuya fuerza expansiva no llega a producir una publicatio de la actividad; lo que no es óbice, en todo caso, para reconocer la aplicación de las reglas del servicio público en ellas. Y con ello se quiere decir que se trata en principio de una actividad privada, y servida por privados, pero que al entrañar un especial interés público o general queda sujeta a una intervención de poderes jurídico-administrativos más intensa de lo que es habitual en el resto de las actividades de esta clase; ello pues si bien es una actividad puramente privada desde el punto de vista del sujeto que la presta, es en cambio una actividad pública, si se tiene en cuenta su finalidad, lo que coincide con su régimen jurídico.

Aunque la doctrina más relevante no esté muy de acuerdo con esta categoría, como Santamaría Pastor ${ }^{75}$, Ariño ${ }^{76}$, De la Cuétara ${ }^{77}$ o el mismo Cassagne ${ }^{78}$, otros también relevantes como Parada ${ }^{79}$, Parejo ${ }^{80}$ y Garrido Falla ${ }^{81}$, la admiten; y en todo caso, todos ellos coinciden en que considerando el titular ejerciente de este "servicio" estamos ante un supuesto de actividad privada, sujeta a ordenaciones de policía especialmente intensa. Particularmente De la Cuétara señala que no constituyen auténticos servicios públicos, sino que en realidad se trata de actividades privadas fuertemente intervenidas por la Administración estatal en virtud de sus potestades de policía administrativa general, las que por su elevada repercusión sobre la vida colectiva se deben someter a una ordenación detallada, reconociendo que en ellas existe una intervención más fuerte de lo habitual del poder público ${ }^{82}$.

\footnotetext{
73 Sin perjuicio de lo detallado, resulta significativo lo establecido como un límite al derecho de propiedad, cuando en el numeral 24 del artículo 19 de la CPR -luego de asegurar a todas las personas el derecho de propiedad en sus diversas especies sobre toda clase de bienes corporales o incorporales- se dispone que solo la ley puede establecer el modo de adquirir la propiedad, de usar, gozar y disponer de ella y las limitaciones y obligaciones que deriven de su función social, y en particular, esta última comprende cuanto exijan los intereses generales de la Nación, la seguridad nacional, la utilidad y la salubridad públicas, y la conservación del patrimonio ambiental.

74 Cassagne (2002) p. 297. También véase en Cassagne (1992) pp. 41-45.

75 Santamaría Pastor (2004) pp. 302-304.

76 Aunque finalmente se coincida con su razonamiento pues efectivamente no estamos en presencia de un genuino servicio público, pero cabe agregar que tampoco estamos en presencia en este caso de una actividad simplemente privada aunque reglamentada, disciplina o programada. AriÑo et al. (2004) pp. 555-561. En igual sentido, véase Ariño OrTIZ (1993) pp. 306-314

77 De la Cuétara (1983) pp. 140-141.

78 Cassagne (2002) p. 299.

79 Parada (2005) pp. 445-447.

80 Parejo Alfonso (2003) p. 671.

81 Garrido Falla (2002) pp. 448-449.

82 De la Cuétara (1983) pp. 227-228.
} 
En cualquier caso, sus notas características ${ }^{83}$ serían las que siguen: se trata de actividades fundamentalmente privadas, no atribuidas ni asumidas a o por la Administración Pública; revisten un interés general; es una actividad dirigida al público de manera indeterminada, o a una colectividad que se encuentra en necesidad y posición de reclamarlo; y las actividades se desarrollan bajo las prescripciones de un régimen especial reglamentario.

Es por ello que, en aquellos casos que se han reconocido como ejemplos de esta figura, no hay actividad publificada, concesión, ni autorización previa, sino una relación de tipo regulatorio entre la Administración y los particulares que en base a distintos instrumentos jurídicos, sustenta un deber de hacer o prestacional, cuyo contenido está predeterminado por la norma jurídica; y cuyo efecto es sujetar esta actividad realizada por privados pero de interés público, a la ordenación de policía ${ }^{84}$.

\subsection{Correlativamente, su vinculación con las obligaciones o cargas de servicio público}

Del mismo modo que en lo anterior, este punto se desgaja de ello y se conecta con la materia estudiada.

En general, las cargas de servicio público se refieren a obligaciones concretas para actividades por lo demás privadas que importan un gravamen de Derecho Público, e implica muchas veces una situación intermedia entre el servicio público y la actividad privada ${ }^{85}$. Como resulta claro a estas alturas, aunque determinadas actividades no reciban la calificación formal de servicio público, se impone sobre ellas esta clase de obligaciones ${ }^{86}$, lo que demuestra que la actividad de servicio público estricto o positivo no es la única respuesta para satisfacer las necesidades individuales y colectivas $^{87}$; de lo que se deriva como posibilidad de afirmación, que lo esencial es la actividad y no el sujeto.

Luego, el funcionamiento de estas obligaciones o cargas de servicio público se concretan en dos niveles: en primer término, de manera abstracta como parte del régimen jurídico de la actividad; y en segundo lugar, cuando es necesario se concretan a través de un clausulado en el título administrativo habilitante o en sus estatutos, dependiendo del caso $^{88}$. Sobre esto mismo, corresponde señalar en esta parte -sin perjuicio de abordarlo con especificidad más adelante-, que se deben distinguir dos clases de obligaciones o cargas: las generales de servicio, destinadas a garantizar el cumplimiento de los principios de prestación (continuidad, regularidad, igualdad y universalidad) ${ }^{89}$; y las especiales de servicio,

\footnotetext{
83 Fernández García (2003) p. 124.

84 Fernández García (2003) p. 125.

85 De la Cuétara (1997) pp. 152-154.

86 Como las denomina Fernández García o Martínez López-Muñiz, como imposición a los operadores de servicios esenciales económicos en red. Véase Fernández García (2003) p. 564, Martínez López-Muñiz (1997) pp. 247-248.

87 Fernández García (2003) p. 566.

88 Villar Rojas (2005) p. 384.

89 Cabe agregar que, como es fácilmente constatable de la realidad ordinaria, la autoridad impone a los operadores de servicios de esta naturaleza, la obligación-carga de hacer accesible la prestación a zonas o usuarios aun cuando ello suponga un costo significativo, el que de todos modos recupera al obtener la misma
} 
impuestas particularizadamente en cada caso de acuerdo a la regulación específica, habitualmente de naturaleza legal y luego reglamentaria, o incluso a través de algún medio o figura contractual.

Muy expresivo, para resforzar lo expuesto, resulta lo señalado por Martínez LópezMuñiz, en el sentido que estos servicios constituyen una técnica jurídico-administrativa elemental que, con sujeción a los principios pro libertate y de subsidiariedad, proporciona soluciones suficientes a problemas actuales de la sociedad ${ }^{90}$.

\section{EL CASO DE LAS JUNTAS DE VIGILANCIA DE RÍOS, FÁCTICA Y NORMATIVAMENTE CONSIDERADO}

\section{Consideraciones iniciales de aplicación de la CATEgoría de SPIP a la ACTIVIDAD DESARROLLADA POR LAS JUNTAS DE VIGILANCIA}

$\mathrm{Al}$ atraer esta categoría jurídica a la actividad que realizan las juntas de vigilancia de los ríos en nuestro país, se pretende explicar cómo debe ejercerse el conjunto de potestades administrativas de que es titular. Y por ello, anteriormente, se afirmó que se sigue en general una noción funcional de servicio público.

Luego, constituye un supuesto jurídico el claro reconocimiento que las juntas de vigilancia en nuestro país constituyen un ejemplo concreto de Administración Corporativa, es decir, de aquellas entidades reconocidas por la doctrina más relevante y reconocida ${ }^{91}$, y caracterizadas del modo que sigue ${ }^{92}$ : son creados o reconocidos y regulados en sus aspectos básicos mediante normas estatales, no en virtud de pacto societario (sin perjuicio que pudiera haberlo); la pertenencia a tales entidades es obligatoria; dichas normas les confían -junto a actividades de puro interés particular de sus miembros- funciones de regulación, disciplina o fomento que, o son típicamente públicas o corresponden a tareas que respecto de otros colectivos son asumidas por la Administración Pública; adicionalmente a la encomienda de dichas funciones públicas, determinados actos de estas entidades son susceptibles de ser recurridos ante la Administración Pública y también ante los Tribunales; y en algunos casos, se les adscribe algún tributo o figura semejante para sostener el funcionamiento de la entidad.

Se hace presente a partir de lo anterior, que aunque tradicionalmente la doctrina chilena las trató como un ejemplo más de corporaciones de Derecho privado simplemente, siempre se les reconocieron ciertas características "especiales" que las diferenciaban de las demás organizaciones de usuarios de aguas; en este trance, lo cierto es que nos encontramos con que las juntas de vigilancia de los ríos realizan claramente actividades materialmente administrativas; a la que la ley le ha atribuido intensas potestades administrativas en cuya

contraprestación pero esta vez de sectores altamente rentables. Acá, la regulación pública se produce para garantizar unas exigencias básicas desde la perspectiva del interés general o colectivo en su caso, que tutela la autoridad administrativa. EsTEVE (2011) p. 480.

90 Martínez López-Muñiz (1997) p. 249.

91 García de Enterría/ Fernández (2006) pp. 393-401; Ariño (2011) pp. 65-71; Parada (2005) pp. 333367; González-Varas (2008) p. 29, y Santamaría (2004) pp. 497-505.

92 Santamaría (2004) p. 499. 
virtud le corresponde realizar actividades materialmente administrativas de ordenación, inspección y sanción ${ }^{93}$.

Así, confluye por un lado noción funcional del servicio público especificada en un servicio privado de interés público, y por otro la calificación como actividad de naturaleza jurídico-administrativa aquella realizada por las juntas de vigilancia de los ríos; constituye una forma de explicar cómo hacen las juntas de vigilancia, es decir, bajo qué condiciones y características realiza o desarrolla sus funciones.

En específico, las aguas -como bien público- son objeto de una intensa regulación interventora de parte de la autoridad pública en especial de la administrativa, además de la cobertura que en su gestión realizan -como actividad administrativa material- las juntas de vigilancia en virtud de las potestades administrativas de que son titulares. Ello por cuanto existe en la función de administración de las mismas, con todo lo que ello conlleva, un claro interés público que se considera debe ser tutelado.

Y como ya se sabe, en este caso quien ejerce de manera normal u ordinaria esa actividad administrativa que se concreta en cargas u obligaciones de servicio, son precisamente las juntas de vigilancia; y solo de manera excepcionalísima y en casos completamente tasados, la ejerce la DGA. Esto se nota, de la revisión de sus normas e incluso de los sistemas de control sobre esas mismas actividades que puede realizarse por parte de la DGA, lo que a la luz de las reglas del servicio público es posible probar adecuadamente. Ello pues, y destacando que a partir de la consideración de las reglas de funcionamiento de los servicios públicos, las mismas claramente se aplican a la actividad realizada por las juntas de vigilancia a este respecto, como son las relativos a la continuidad, regularidad, igualdad y universalidad; todos los que se cumplen en este caso, como se verá enseguida.

Pues bien, ocurre que en el caso de las juntas de vigilancia -en virtud de las competencias asignadas, y las potestades conferidas- estamos ante la clara presencia de una actividad concretada en prestaciones de tipo específico que se pasan a desarrollar. Cabe aclarar que esta actividad es prestada ab initio sin habilitación por acto administrativo alguno de delegación, sino que realizada en virtud de una habilitación legislativa que asigna potestades administrativas y que se traduce en un conjunto de técnicas concretas, a favor de esta específica organización privada. De todas maneras se encuentra sujeta a su supervigilancia aunque con algunas particularidades, por parte de la Dirección General de Aguas.

En dicha virtud, a lo menos en este sentido y respecto de la actividad de distribución que nominalmente concentra todas sus potestades, las juntas de vigilancia realizan dicha actividad con claros caracteres de un servicio público general, aplicable normativamente a los servicio privado de interés público.

Luego, y como punto en concreto de análisis de este específico ejemplo de SPIP, cabe afirmar que existe en la actividad desarrollada por las juntas de vigilancia claros caracteres y aplicación de las reglas de funcionamiento ya señaladas predicables de todo servicio público -como son la continuidad, regularidad, igualdad y universalidad- los que en cada caso adquirirán sus especificidades propias.

93 Sobre esto, véase Rojas Calderón (2010) pp. 401-456. 
2. Su Fundamentación en la medida DEL DERECHO DE APROVEChamiento DE AGUAS

Lo dicho se basa en la unidad o medida del derecho de aprovechamiento de aguas, y el modo en que se cumple por los operadores del sistema, la entrega de las aguas a partir de esa expresión volumétrica.

Cabe dejar constancia que la cuestión acerca de la medida del derecho de aprovechamiento de aguas ha sido objeto de varias consideraciones ${ }^{94}$; sin embargo, donde considero que debe colocarse el acento en esta oportunidad es en la regla de la proporcionalidad (o prorrata) como base de la actividad, y luego a propósito de la clasificación de los derechos de aprovechamiento de aguas.

\subsection{La proporcionalidad, como regla jurídica ${ }^{95}$}

La proporcionalidad de la distribución de aguas, es uno de los cuatro principios del Derecho de Aguas chileno, y el específicamente aplicable en el reparto -sistema alícuota-, donde se trata de atender a la cuestión de la medida o canon que, de modo general, corresponde utilizar para la entrega o reparto de las aguas; ello pues la entrega correspondiente del recurso hídrico de acuerdo a los derechos que se tengan en el cauce natural y de acuerdo a la naturaleza de tales derechos, es el principio básico de gestión de este bien. Y lo anterior tiene una especialísima implicancia en la actividad que desempeñan los organismos encargados de realizarla, particularmente en la distribución de las aguas realizada por las juntas de vigilancia.

En general, es posible conceptuarla como la conformidad de unas partes con el todo, o de cada una de las cosas integrantes de ese total relacionadas entre sí. Y, en particular en relación con la gestión de los recursos hídricos continentales, se puede decir que es el modo de distribución de las aguas de la forma más equitativa posible y en proporción a la cantidad de agua que corresponde a cada derecho de acuerdo a su título o, en caso de no ser posible abastecer la totalidad de ellos, en proporción a la cantidad total de agua que se disponga en la fuente.

Esto se ratifica normativamente, en virtud de lo dispuesto en el artículo 6 inciso $2^{\circ}$ y artículo $7 \mathrm{CAg}$, que junto con señalar que el derecho de aprovechamiento es de dominio de su titular, quien podrá usar, gozar y disponer de él, señala enseguida que este derecho se expresa en volumen por unidad de tiempo fijado en el título; en relación con el artículo 17 que sostiene que los derechos de aguas facultan para usar el agua en la dotación que corresponda, salvo que la fuente de abastecimiento no contenga una cantidad suficiente para satisfacerlos de manera total, caso en el cual se distribuirán las aguas en partes alícuotas, o sea, proporcionalmente. Se complementa esto con la presunción del artículo 309 que dispone que los derechos otorgados con anterioridad a la entrada en vigencia del Código y que no estén expresados en volumen por unidad de tiempo, se entenderán equivalentes al caudal máximo aprovechado en los cinco años anteriores a la fecha en que se produzca controversia sobre la cuantía; lo que ineludiblemente hace necesario su perfeccionamiento

94 Vergara Blanco (1996) pp. 39-69; y Santelices Narducci (2002) pp. 109-192.

95 Rojas Calderón (2010) pp. 96-97. 
conforme el procedimiento regulado en los artículos 44 a 46 del Reglamento del Catastro Público de Aguas en relación con el artículo 177 del CAg, esto es, en vía judicial y conforme el procedimiento sumario.

Luego, esto se ratifica en la medida que el artículo 12 del CAg distingue entre varios tipos o categorías de derechos de aprovechamiento de aguas, a saber: consuntivos o no consuntivos, de ejercicio permanente o eventual; y pueden ser continuos, discontinuos o alternados con otras personas; mismas calificaciones que en cada caso particular pasan a caracterizarlo. Esto se desarrolla entre los artículos 13 a 19 del mismo código.

En fin, refrenda todo lo dicho el artículo 314 inciso $7^{\circ}$ que trata acerca de la declaración de zona de escasez en caso de sequía extrema -declaradas formalmente ambas situaciones-, e intervenido el cauce y suspendidas las atribuciones de las juntas de vigilancia, se dispone que en caso que el titular de un derecho de aprovechamiento de aguas recibiera menor proporción de aguas que la que le corresponda de acuerdo a las disponibilidad de aguas existentes, tendrá derecho a ser indemnizado por el Fisco de Chile, que es la representación patrimonial de la Administración Pública.

A través de la operatividad de esta regla del modo visto, entonces, se concreta el principio de regularidad e igualdad.

\subsection{Caracterización del derecho y su importancia en la fórmula de la medida}

$\mathrm{Al}$ efecto conviene recordar lo establecido en el artículo $6 \mathrm{CAg}$, conforme el cual:

El derecho de aprovechamiento es un derecho real que recae sobre las aguas y consiste en el uso y goce de ellas, con los requisitos y en conformidad a las reglas que prescribe este código.

El derecho de aprovechamiento sobre las aguas es de dominio de su titular, quien podrá usar, gozar y disponer de él en conformidad a la ley.

De particular importancia tiene la facultad de uso para esta caracterización, configurada anteriormente, en cuya virtud se permite que el titular pueda utilizar y servirse de la cosa, y especialmente sobre las aguas se admite claramente su aprovechamiento, lo que implicará en el caso de los derechos consuntivos el consumo material del bien sobre que recae esta titularidad administrativa; y en el caso de los no consuntivos, su aplicación a una fuerza motriz.

Sea uno u otro caso, el uso del agua implica su consumo conforme sus características al agotarse la potencialidad que emana del título.

Luego, el artículo 7 CAg, establece la base de esta medida, en tanto establece la exigencia correspondiente, del modo que se indica:

\section{El derecho de aprovechamiento se expresará en volumen por unidad de tiempo.}

Enseguida en los artículos 16, 17 y 18, se hace referencia a los derechos de ejercicio permanente. Y así pues, conforme el artículo 16 CAg la caracterización fundamental de los derechos de aprovechamiento de aguas, y correspondiente con la forma de uso básica y 
habitual de los títulos de aguas -ejercicio permanente- (aunque no necesariamente correspondiente con la dotación de aguas), se basa en lo que se dispone del modo que sigue:

Son derechos de ejercicio permanente los que se otorguen con dicha calidad en fuentes de abastecimiento no agotadas, en conformidad a las disposiciones del presente código, asi como los que tengan esta calidad con anterioridad a su promulgación.

Los demás son de ejercicio eventual.

Luego, en el artículo 17 se establece la definición básica de las atribuciones correspondientes al titular de dichos derechos de ejercicio permanente, del modo que se expresa:

Los derechos de aprovechamiento de ejercicio permanente facultan para usar el agua en la dotación que corresponda, salvo que la fuente de abastecimiento no contenga la cantidad suficiente para satisfacerlos en su integridad, en cuyo caso el caudal se distribuirá en partes alícuotas.

En fin, complementariamente, el artículo 18 establece lo mismo, pero respecto del titular de derechos de ejercicio eventual, conforme se indica a continuación:

Los derechos de ejercicio eventual solo facultan para usar el agua en las épocas en que el caudal matriz tenga un sobrante después de abastecidos los derechos de ejercicio permanente.

Las aguas lacustres o embalsadas no son objeto de derechos de ejercicio eventual.

El ejercicio de los derechos eventuales queda subordinado al ejercicio preferente de los derechos de la misma naturaleza otorgados con anterioridad.

Por otro lado, pero continuando con la delimitación de la medida del derecho de aprovechamiento de aguas, resulta esencial a nuestros efectos el artículo 19, en atención a que fija el modo en que son atendidos los repartos de los derechos de aprovechamiento, conforme se explica en su propio texto.

Son derechos de ejercicio continuo los que permiten usar el agua en forma ininterrumpida durante las veinticuatro horas del día.

Los derechos de ejercicio discontinuo solo permiten usar el agua durante determinados periodos.

Los derechos de ejercicio alternado son aquellos en que el uso del agua se distribuye entre dos o más personas que se turnan sucesivamente.

Esto es importante, pues tanto el artículo $140 \mathrm{CAg}$, referido a la solicitud de derecho de aprovechamiento de aguas, en su numeral 5 atiende a los requisitos específicos indicados. Y también el artículo 149, relativo al acto administrativo constitutivo del derecho de aprovechamiento de aguas, refiere en el numeral 6 a las características antedichas. 
Por último, conviene citar el artículo 24, por las enormes implicancias que pueden tener el mismo.

Si el acto de constitución del derecho de aprovechamiento no expresa otra cosa, se entenderá que su ejercicio es continuo. Si se constituye el derecho como de ejercicio discontinuo o alternado, el uso solo podrá efectuarse en la forma y tiempo fijados en dicho acto.

En efecto, dado que la mayoría de los derechos y demás titularidades equivalentes son anteriores a 1981, aunque incluso no se hayan formalizado, resueltas que la mayor cantidad de derechos de aprovechamiento de aguas existentes en nuestro país son continuos ${ }^{96}$.

Conforme estas reglas, se concretan los principios y reglas de continuidad, regularidad e igualdad y no discriminación.

\subsection{La fuerza de la realidad}

Sin embargo, a pesar de las normas citadas y de lo sostenido adicionalmente a partir de ellas, es la realidad la que fija los matices en este ámbito.

Ello pues conforme se verá, las juntas de vigilancia si bien deben respetar en las medidas de distribución de los derechos las aguas correspondientes a las titularidades respectivas, no obstante, pueden establecerse medidas extraordinarias, atendido el hecho que no exista agua suficiente para atender a todos de acuerdo a su título. En ese caso, aparecerá la regla jurídica de la proporcionalidad o prorrata en el reparto de las aguas, operando ya no en la abundancia, sino en la escasez.

En este sentido es muy relevante para hacer el servicio correspondiente al reparto, tanto al ordinario tanto como al extraordinario, el control que esta ejerza en las obras hidráulicas que constituyan sus medios de control.

Particularmente significativo a este respecto, resulta ser el artículo 38 CAg que dispone lo siguiente:

Las organizaciones de usuarios o el propietario exclusivo de un acueducto que extraiga aguas de una corriente natural, estarán obligados a construir, a su costa, a lo menos una bocatoma con compuertas de cierre y descarga y un canal que permita devolver las aguas o su exceso al cauce de origen, además de los dispositivos que permitan controlar y aforar el agua que se extrae.

\footnotetext{
${ }_{96}$ No deja de llamar la atención que en una atribución tan fuertemente estatal como es la de determinar los hechos gravados con impuestos y sus sujetos, como ocurre con la atribución concedida a la Dirección General de Aguas en los artículos 129 bis 4 y bis 5, se establezca una consulta a la organización de usuarios respectiva, en el artículo 129 bis 8, en cuya virtud: Corresponderá al Director General de Aguas, previa consulta a la organización de usuarios respectiva, determinar los derechos de aprovechamiento cuyas aguas no se encuentren total o parcialmente utilizadas, al 31 de agosto de cada año, para lo cual deberá confeccionar un listado con los derechos de aprovechamiento afectos a la patente, indicando el volumen por unidad de tiempo involucrado en los derechos. En el caso que los derechos tengan obras de captación, se deberá señalar la capacidad de dichas obras y se individualizará la resolución que las hubiese aprobado. En ello tiene enorme relevancia lo que puedan decir las juntas de vigilancia, especialmente a partir de la exigencia establecida en el artículo 38 a cuyo cargo se encuentra dicho control.
} 
De esta manera, tenemos disposiciones que fijan características de los derechos, realidad hídrica, potestades administrativas unidas a sus técnicas correspondientes, y medios materiales para poder realizar sus tareas.

\section{EN CONSECUENCIA, EL SERVICIO PRIVADO DE INTERÉS PÚBLICO (SPIP) REALIZADO POR LAS JUNTAS DE VIGILANCIA}

1. La ACtividad de distribución de LAS aGUAS, COMO CONCRECión DE REGLAS DEL SERVICIO PÚBLICO

Esta actividad material, igual que en el caso anterior, debe realizarse ceñida a las normas que contemplan sus atribuciones y potestades, lo que -ya podrá apreciarse- configura un claro segundo ejemplo de servicio privado de interés público en nuestro Derecho.

Enseguida, siguiendo la tónica anterior, si se trata de decir cómo hacen las juntas de vigilancia, habrá que estarse a lo que establecen sus disposiciones habilitantes; de manera que al mismo tiempo que se atribuyen potestades administrativas a las juntas de vigilancia, su otra faz es la de una verdadera carga u obligación de prestar un servicio, sujeto por cierto a las reglas antes vistas.

Al efecto, cabe recordar que el artículo 266 establece el objeto de las juntas de vigilancia del modo que sigue:

Las juntas de vigilancia tienen por objeto administrar y distribuir las aguas a que tienen derecho sus miembros en las fuentes naturales, explotar y conservar las obras de aprovechamiento común y realizar los demás fines que les encomiende la ley.

Podrán construir, también, nuevas obras relacionadas con su objeto o mejorar las existentes, con autorización de la Dirección General de Aguas.

Esta disposición establece el marco teleológico de las atribuciones y deberes en la terminología legal -al fin, potestades- de que son titulares.

Enseguida, para verificar lo correspondiente a esta apartado, primeramente se pasará revista a dichas disposiciones y enseguida se analizarán las clases de prestaciones correspondientes.

\section{CARGa DE DisTRIBUCIÓN CONFORME MEDIDAS ORDINARIAS}

\subsection{Atribución matriz}

Lo que primeramente cabe señalar con relación a este punto, es que el reparto de las aguas y demás medios de que disponen las juntas de vigilancia, pueden ejercerse en situación de poder atender o cubrir completamente los derechos de aguas correspondientes a su competencia.

Acá se concreta una potencia -el derecho de aprovechamiento de agua en cuanto título- antes de ejercer el derecho y sigue vigente una vez que se ejerce. Lo que ocurre es que en uno y otro caso, se ejerce el derecho agotando materialmente la cosa en un instante, 
pero dada su naturaleza la cosa no se consume jurídicamente. Por lo mismo, el derecho de aprovechamiento de aguas es una titularidad administrativa que se concreta en una potencia de una medida determinada aguas, para ejercer en un cauce, con un volumen y tiempo asignado, y con unas características también determinadas de acuerdo a su título o la ley.

En ese caso, en que serán atendidos todos los derechos de sus integrantes en la totalidad de la dotación asignada de acuerdo al máximo de su potencialidad, habrá distribución "ordinaria" donde se tomarán las medidas correspondientes, satisfaciéndose de este modo completamente el derecho por medio de la entrega de las aguas que le corresponden de acuerdo a su derecho.

A este respecto, cabe atender lo dispuesto en el artículo 274 CAg que contiene las atribuciones y deberes matrices en este ámbito del Directorio de las juntas de vigilancia, el que en su numeral 1 dispone la siguiente carga:

Vigilar que la captación de las aguas se haga por medio de obras adecuadas y, en general, tomar las medidas que tiendan al goce completo y a la correcta distribución de los derechos de aprovechamiento de aguas sometidos a su control.

Esta atribución es complementada por la primera parte del numeral 2 del mismo artículo, en cuya virtud constituye igualmente atribución y deber del Directorio:

\section{Distribuir las aguas de los cauces naturales que administre (...).}

Ello garantiza la continuidad, en virtud de la evidente necesidad y exigencia del funcionamiento ininterrumpido del servicio; pues en caso contrario no se podría gozar completa y correctamente de los derechos. Lo que es coincidente o connatural a las aguas que escurren por cauces naturales que son "corrientes", es decir escurren permanentemente y sin detenerse jamás.

En esta parte, cabe recordar lo dispuesto en el artículo 17 y 19 respecto de las características de permanencia y continuidad de los derechos de aprovechamiento de aguas, referidas fundamentalmente al servicio de cobertura de los mismos.

Luego, su interrupción, solo se podría justificar en caso de fuerza mayor que le dejen en una situación de imposibilidad de continuar la prestación.

Hay en ello, como queda evidencia, concreción de reglas generales de los servicios públicos.

\subsection{Concreción en actividad}

Enseguida, conforme el artículo $278 \mathrm{CAg}$, los repartidores de agua deberán cumplir los acuerdos del directorio sobre distribución de aguas, turnos y rateos, conforme a los derechos establecidos.

Lo que es consecuencia del principio de regularidad en la prestación, toda vez que esta deberá hacerse respetando las entregas totales o parciales, dependiendo si el río se encuentra con su disponibilidad completa o no, en cuyo caso se utiliza normalmente el sistema de turnos de entrega. Esto debe ser, además, realizado considerando las características 
de cada derecho de aprovechamiento de aguas, y por tanto habrá que ver si es consuntivo o no, si es de ejercicio permanente o eventual, y si es de ejercicio continuo, discontinuo o alternado, en cada caso.

Adicionalmente, lo anterior se debe hacer siguiendo la regla de la igualdad y la regla de la universalidad. Ello en atención a que claramente el artículo 272 establece que si por otorgamiento de derechos, construcción de nuevas obras de riego o de regulación de la cuenca se constituye un nuevo derecho de agua, el que lo goce quedará incorporado a la junta de vigilancia respectiva; lo que tiene la contrapartida en virtud del artículo $274 \mathrm{CAg}$ consistente en que el directorio de la junta de vigilancia debe velar porque se respeten los derechos de agua en el prorrateo del caudal matriz, impidiendo que se extraigan aguas sin títulos. E igualmente, conforme el mismo artículo, deberá distribuir las aguas de los cauces naturales que administre, declarar su escasez y, en este caso, fijar las medidas de distribución extraordinarias con arreglo a los derechos establecidos y suspenderlas.

En fin, conforme lo dispuesto en el artículo 278, al repartidor de agua le corresponderá cumplir los acuerdos del directorio sobre distribución de aguas, turnos y rateos, conforme a los derechos establecidos y restablecerlos inmediatamente, cuando sean alterados por actos de cualquier persona o por accidente casual, denunciando estos hechos al directorio.

Por último, de acuerdo al artículo 279, le corresponde a los celadores:

(...) la policía y vigilancia para la justa y correcta distribución de las aguas, con arreglo a los derechos establecidos y a los acuerdos adoptados, debiendo dar cuenta inmediata de toda alteración o incorrección que notaren.

Lo antes revisado constituye pues una garantía material de resguardo de las reglas antedichas. Tanto, que en caso contrario, es decir, cuando no se respetaran dichas reglas, deberá darse cuenta inmediata de toda alteración o incorrección tanto en las medidas ordinarias como en las extraordinarias, así como en relación a cualquier otra alteración que vulnere las decisiones del Directorio en uso de sus atribuciones legales.

Luego, por medio de estas atribuciones, se concretan las cargas asociadas a reglas de servicio público, del tipo ya destacado.

\section{CARGA EN LA DisTRIBUCIÓN CONFORME MEDIDAS EXTRAORDINARIAS}

\subsection{Fundamento de la atribución}

Como fue definido anteriormente, el sistema de prorrata consiste en el modo de distribución de las aguas de la forma más equitativa posible y en proporción a la cantidad de agua que corresponde a cada derecho de acuerdo a su título o, en caso de no ser posible abastecer la totalidad de ellos, en proporción a la cantidad total de agua que se disponga en la fuente.

Esta es la situación que ocurre cuando no es posible entregar la dotación total, y por consiguiente que amerita una medida "rebajada" de entrega, lo que implicará cubrir proporcionalmente los derechos. 
En virtud de lo anterior, y de acuerdo a lo dispuesto en el artículo $274 \mathrm{~N}^{\circ} 2$ es atribución del Directorio de la junta de vigilancia:

(...) declarar su escasez y, en este caso, fijar las medidas de distribución extraordinarias con arreglo a los derechos establecidos y suspenderlas.

Como ya fue visto anteriormente, la declaración de escasez de las aguas, así como la suspensión de las medidas de distribución extraordinarias, deberán hacerse por el Directorio en sesión convocada especialmente para tal efecto.

\subsection{Correlación de dicha atribución y deber}

A este respecto, cabe reiterar lo ya dicho precedentemente acerca de la concreción en actividad de repartidores y celadores, ahora referida su actividad a estas medidas extraordinarias.

En efecto, a lo ya dicho, cabe agregar especialmente el artículo 281, de singular ocurrencia en casos cada vez más comunes de sequía ordinaria o extraordinaria, que son las situaciones que ameritan precisamente la aplicación de este caso de medida extraordinaria de distribución, en cuya virtud:

El que sacare agua fuera de su turno o alterare de cualquier manera la demarcación prescrita por el directorio o por el repartidor, será privado del agua por tiempo o cantidad doble al abuso cometido.

Conforme lo anterior, se sanciona especialmente -multa y suspensión del derecho, como expresión de su potestad sancionatoria- a los que alteraran los turnos o dispositivos de distribución de las aguas.

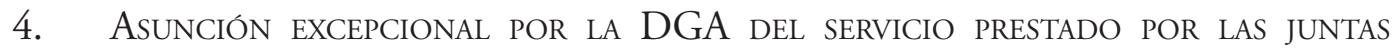
DE VIGILANCIA

Esto puede ocurrir solo en dos situaciones debidamente tasadas, a saber: en caso de sequía extraordinaria, previa declaración formal en tal sentido, siempre que los usuarios no se hubieran puesto de acuerdo en la distribución, y bajo el cumplimiento de todos los demás supuestos allí señalados; en caso de faltas graves o abuso o dejación o negligencia en el cumplimiento de este servicio.

Dado que resulta pertinente a lo analizado en este trabajo el segundo caso, solo se analizará este último.

En efecto, conforme lo dispuesto en el artículo 283 y 291 CAg si en una organización de usuarios se hubiesen cometido faltas graves o abusos por el directorio o administradores en la distribución de las aguas, o en la gestión económica cualquiera de los afectados podrá solicitar la fiscalización de la Dirección General de Aguas. Luego del procedimiento correspondiente, conforme el artículo 290 CAg, si se verifican las faltas o abusos denunciados, la DGA deberá requerir al directorio o administradores para que se corrijan las anomalías en el plazo que al efecto indique. 
Ahora bien, de acuerdo a lo dispuesto en el artículo 293 CAg, si continuaren los errores, faltas o abusos denunciados, la misma DGA podrá solicitar a la Justicia Ordinaria que decrete la intervención por dicho organismo en la distribución de las aguas, por períodos que no excedan de noventa días, con todas las facultades (potestades) de los respectivos directores o administradores.

Finalmente, esas facultades, atribuciones o más bien títulos de potestad serán ejercidas por la o las personas que designe la Dirección General de Aguas, quien actuará con el título de interventor. Para el nombramiento del mismo, se requerirá el nombramiento a la justicia ordinaria, quien en un procedimiento sumarísimo, hace la designación y fija el tiempo de la intervención a propuesta del servicio.

\section{CONCLUSIONES}

Al finalizar este trabajo, se estima posible arribar al siguiente grupo de conclusiones:

1. La actual configuración de los servicios públicos dista mucho de categorizaciones organicistas, sino que actualmente atiende más bien a concepciones cada vez más funcionalistas, de la mano sobre todo de las elaboraciones realizadas por el Derecho de la regulación económica, antes que de un Derecho Administrativo tradicional marcadamente subjetivista.

Ello, antes que ser un desmedro para los ciudadanos, constituye su garantía en la medida que la extensión del Derecho Administrativo a esas áreas privatizadas constituye, sobre todo, su garantía.

Lo anterior, de todos modos tiene repercusiones en el reconocimiento y configuración de unos servicios públicos de variado tipo, destacando en este trabajo el reconocimiento de la categoría de los servicios privados de interés público (SPIP), los que se encuentran sujetos de todos modos a las reglas generales aplicables a todos los servicios públicos.

2. Un caso concreto, es el de las juntas de vigilancia de ríos, que siendo organizaciones privadas ordenadas en torno a las titularidades de derechos de aprovechamiento de aguas, han recibido el mandato por parte de la ley de administrar y distribuir las aguas y los derechos, actuando verdaderamente como la "administración pública" del sector.

Para ello, son titulares al mismo tiempo de enormes potestades administrativas que les atribuyen poderes de ordenación, inspección y sanción; y actúan sujetos a cargas u obligaciones de servicio público emanados de la aplicación de las medidas de distribución, ordinaria o extraordinariamente.

Se configura, de este modo, un claro ejemplo de SPIP.

3. Con ello se prueba dogmáticamente, a partir del caso analizado, la existencia plena de la categoría de los Servicios Privados de Interés Público (SPIP), tanto fáctica como normativamente en nuestro Derecho. 


\section{BIBLIOGRAFÍA}

Ariño Ortiz, G. (1993): Economía y Estado. Crisis y reforma del sector público (Madrid, Marcial Pons) $422 \mathrm{pp}$.

Ariño Ortiz, G. et al. (2004): Principios de Derecho Público Económico (Granada, Comares) $1089 \mathrm{pp}$.

Ariño Ortiz, G. (2011): "Sobre el concepto de Administración y el Derecho Derecho Administrativo”. En ÉL MISMO. Lecciones de Administración (y politicas públicas) (Madrid, Iustel) pp. 50-83.

Bermúdez Soto, J. (2007): Fundamentos de Derecho Ambiental (Valparaíso, Ediciones Universitarias de Valparaíso. Pontifica Universidad Católica de Valparaíso) 285 pp.

Bermúdez Soto, J. (2010): Derecho Administrativo General. (Santiago, Abeledo-Perrot LegalPublishing) $349 \mathrm{pp}$.

Braconnier, S. (2003): Droit des services publics (Paris, Presses Universitaires de France. PUF) $531 \mathrm{pp}$.

Camacho Cepeda, G. (2007): "La actividad administrativa de servicio público". En Pantoja Bauzá, R. (coord.). Derecho Administrativo chileno (México D.F.: Porrúa) pp. 458-478.

Camacho Cepeda, G. (2010): Tratado de Derecho Administrativo. La actividad sustancial de la Administración del Estado, tomo IV (Santiago, Abeledo-Perrot - LegalPublishing) 457 pp.

Cassagne, J. C. (1992): La intervención administrativa (Buenos Aires, Abeledo-Perrot) 222 pp.

Cassagne, J. C. (2002): Derecho Administrativo, tomo II (Buenos Aires, LexisNexis - Abeledo-Perrot) $662 \mathrm{pp}$.

Cazor Aliste, K. / Cortés Moreno, G. (2012): “Las indefiniciones teóricas y dogmáticas del derecho de huelga en Chile”. En Aguilar Cavallo, G. (coordinador). Derechos económicos, sociales y culturales en el orden constitucional chileno (Santiago, Librotecnia) pp. 245-256.

Chevalier, J. (2003): Le service public (Paris, PUF) 126 pp.

Cordero Vega, L. (2012): "Sobre la lógica del control judicial de la Administración". Disponible en <http://www.elmercurio.com/Legal/Noticias/Analisis-Juridico/2012/10/01/ Sobre-la-logica-del-control-judicial-de-la-Administracion.aspx> [06 de abril de 2013].

De la Cuétara, J. M. (1983): La actividad de la Administración (Madrid, Tecnos) 605 pp.

De la Cuétara, J. M. (1997 a): “Tres postulados para el nuevo servicio público”. En Ariño, G. / De la Cuétara, J. M. / Martínez López-Muñoz, J. L. El nuevo servicio público (Madrid, Marcial Pons) pp. 107-182.

De la Cuétara, J. M. (1997 b): “Aproximación a la regulación de servicio público como nuevo paradigma para la prestación de servicios económicos”. En Ariño, G. / De la Cuétara, J. M. / Martínez López-Muñoz, J. L. El nuevo servicio público (Madrid, Marcial Pons) pp. 87-106.

Entrena Cuesta, R. (1958): "El servicio de taxis". RAP No 27, pp. 29-61.

Esteve Pardo, J. (2008): Derecho del Medio Ambiente (Madrid: Marcial Pons) 276 pp.

Esteve Pardo, J. (2010): "La recepción en la Europa continental del Derecho de la regulación de la economía (Regulierungsrecht. La sistemática de la doctrina alemana y sus 
sustanciales analogías con la recepción doctrinal en España. Crónica de libros)". RAP No 183 , pp. 295-307.

Esteve Pardo, J. (2011): Lecciones de Derecho Administrativo (Madrid: Marcial Pons) 581 pp. Esteve Pardo, J. (2012): "La extensión del Derecho Público. Una reacción necesaria". RAP No 189, pp. 11-40.

Fernández García, Ma. Y. (2003): Estatuto jurídico de los servicios esenciales económicos en red (Madrid: Ciudad Argentina-INAP) 650 pp.

García de Enterría, E. / Fernández, T-R (2006): Curso de Derecho Administrativo, tomo $I$ (Madrid, Civitas) 843 pp.

Garrido Falla, F. (2002): Tratado de Derecho Administrativo, tomo I (Madrid, Tecnos) 742 pp.

Jèze, G. (1928): Los principios generales del Derecho Administrativo. (trad. C. García Oviedo, Madrid, Editorial REUS) 567 pp.

Lachaume, J.-F. (1989): Grands services publics (Paris, Masson) 375 pp.

Linotte, D. y Mestre, A. (1982): Services publics et Droit Public Economique (Paris, Litec Droit) p. 49.

Martínez López-Muñiz, J. L. (1997): “La regulación económica en España”. En Ariño, G. / De la Cuétara, J. M. / Martínez López-Muñoz, J. L. El nuevo servicio público (Madrid, Marcial Pons) pp. 183-262.

Muñoz Machado, S. (1997): Servicio público y Mercado. I.- Los fundamentos (Madrid, Civitas) $328 \mathrm{pp}$.

Nallar Dera, D. (2010): Regulación y control de los servicios públicos (Buenos Aires, Marcial Pons) 518 pp.

Pantoja BauzÁ, R. (1998): La organización administrativa del Estado (Santiago, Editorial Jurídica de Chile) 477 pp.

Nieto, A. (1991): "La Administración sirve con objetividad los intereses generales". En Martín-Retortillo, S. (coord..). Estudios sobre la Constitución Española. Homenaje al Profesor Eduardo García de Enterría, tomo III (Madrid, Civitas) pp. 2185-2254.

Parada, R. (2005): Derecho Administrativo I. Parte general (Madrid, Marcial Pons) 782 pp.

Parada, R. (2005): Derecho Administrativo II: Organización y empleo público (Madrid, Marcial Pons) 622 pp.

Parejo Alfonso, L. (2003): Derecho Administrativo (Barcelona, Ariel) 1347 pp.

Rodríguez-Arana, J. (2012): Interés general, Derecho Administrativo y Estado del bienestar (Madrid, Iustel) $240 \mathrm{pp}$.

Rojas Calderón, C. (2010): La distribución de las aguas en el Derecho chileno. La actividad desarrollada por las juntas de vigilancia. Tesis doctoral, Facultad de Derecho de la Pontificia Universidad Católica de Chile (no publicada) 539 pp.

Santamaría Pastor, J. A. (2004): Principios de Derecho Administrativo General I (Madrid, Iustel) $831 \mathrm{pp}$.

Santamaría Pastor, J. A. (2004): Principios de Derecho Administrativo General II (Madrid, Iustel) 796 pp.

Santelices Narducci, H. (2002): Medida del derecho de aprovechamiento de aguas (Santiago, Editorial Metropolitana) 206 pp. 
Sarmiento García, J. (1994): "Noción y elementos del servicio público". En González de Aguirre, M. (coordinadora). Los servicios públicos. Régimen jurídico actual (Buenos Aires, DePalma) pp. 1-20.

Sendín García, M. A. (2003): Hacia un servicio público europeo. El nuevo Derecho de los servicios públicos (Granada, Comares) $353 \mathrm{pp}$.

Silva Cimma, E. (1995): Derecho Administrativo chileno y comparado. El servicio público (Santiago, Editorial Jurídica de Chile) 323 pp.

Vergara Blanco, A. (1996): "Régimen jurídico de la unidad de medida de los derechos de aguas, su esencial conexión con la distribución de las aguas superficiales". Revista de Derecho de Aguas, Universidad de Atacama, Vol. VII, pp. 39-69.

Vergara Blanco, A. (2004): "El nuevo servicio publico abierto a la competencia: De la publicatio al libre acceso. Coherencia de las viejas técnicas concesional y autorizacional”. RDAE No 12, pp. 33-49.

Villar Palasí, J. L. (1964): La intervención administrativa en la industria (Madrid, Instituto de Estudios Políticos) 438 pp.

Villar Rojas, F. (2004): Las instalaciones esenciales para la competencia. Un estudio de Derecho Público Económico (Granada, Comares) 410 pp.

Zegarra Valdivia, D. (2005): El servicio público. Fundamentos (Lima, Palestra) 368 pp.

Zúniga Urbina, F. / Sepúlveda Rodríguez, E. (2010): "La Huelga en la Constitución. El caso de los trabajadores de empresas de servicio”. En Nogueira Alcalá, H. (coord.) Dogmática y aplicación de los derechos sociales (Santiago, Librotecnia) pp. 401-422. 